\title{
Notes on Japanese Terms
}

1. All Japanese personal names are in Japanese order, surnames first, except for those of authors published in English.

2. Except in familiar place names and names from English-language publications, macrons indicate long vowels.

3. In romanized names and titles of documents written or published before 1945, I have used the word "Nippon" (Japan). For documents that have appeared after that year, I have used "Nihon." 